Synlett

\title{
Hypophosphorous Acid
}

\section{Kai Gao}

Synlett 2015, 26, 133.

The scheme given along with abstract (B) was erroneously inserted in this place.

The correct scheme is given below. We apologize for this production error.

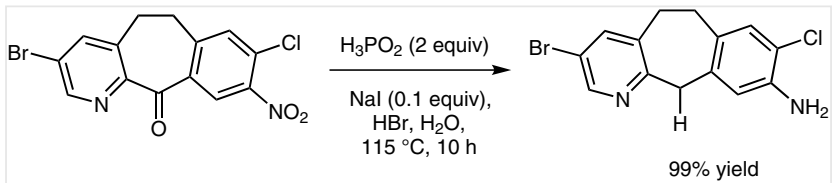

